\title{
Protection against Acute and Chronic Hyperoxic Inhibition of Neonatal Rat Lung Development with the 21-Aminosteroid Drug U74389F
}

\author{
LEE FRANK AND GWENN E. MCLAUGHLIN \\ Pulmonary Research Center, Departments of Medicine and Pediatrics, University of Miami School of Medicine, \\ Miami, Florida 33101
}

\begin{abstract}
Normal lung development involves septation of the large air saccules present at birth to form smaller diameter alveoli with a much increased surface area for respiratory exchange. This process in the newborn animal is markedly inhibited by hyperoxia, and the altered lung morphology that results may be permanent. We tested whether treatment of neonatal rats with the new 21-aminosteroid (21-AS) drug, U-74389F (15 mg/kg/d), could protect against $\mathrm{O}_{2}$-induced inhibition of normal lung development. By morphometric analysis after $10 \mathrm{~d}$ in $>95 \%$ $\mathrm{O}_{2}$, the lungs of the animals treated with this potent iron chelator and inhibitor of lipid peroxidation showed a substantial protective effect-with reduced mean air space diameter and significantly increased internal surface area compared with $\mathrm{O}_{2}$ control pups. [Air control mean air space diameter $=47.4 \mu \mathrm{m}$, internal surface area $=1014 \mathrm{~cm}^{2} ; \mathrm{O}_{2}$ controls $=61.0 \mu \mathrm{m}(\uparrow 29 \%), 769 \mathrm{~cm}^{2}(\downarrow 24 \%) ; \mathrm{O}_{2} 21-\mathrm{AS}=$ $53.4 \mu \mathrm{m}(\uparrow 13 \%), 919 \mathrm{~cm}^{2}(\downarrow 9 \%) ; p<0.05$ between $\mathrm{O}_{2}$ groups.] Similarly, inhibition of lung elastin deposition (involved in septation process) during hyperoxia was significantly ameliorated by 21-AS treatment. In addition, follow-up studies of young adult rats demonstrated permanently enlarged lung alveoli and reduced surface area after neonatal high $\mathrm{O}_{2}$ exposure. These chronic morphologic effects were also significantly reduced by neonatal 21-AS treatment. The right ventricle hypertrophy $\left(2^{\circ}\right.$ to pulmonary hypertension) in the $\mathrm{O}_{2}$ controls reaching adulthood [right ventricle/left ventricle + septum weight $=\mathbf{0 . 4 9 6}$ $(\uparrow 55 \%$ versus air control value $=0.320)]$ was markedly reduced in the adult 21-AS animals exposed to hyperoxia as neonates $[0.382(\uparrow 19 \%)]$. Thus, $21-\mathrm{AS}$ treatment had a substantial protective effect against both the acute and chronic lung as well as cardiac morphologic changes that early life exposure to hyperoxia can produce. (Pediatr Res 33: 632-638, 1993)
\end{abstract}

\section{Abbreviations}

21-AS, 21-aminosteroid (U74389F)

$\mathrm{L}_{\mathrm{M}}$, mean linear intercept (mean lung air space diameter) ISA, internal surface area

AOE, antioxidant enzyme

Received November 18, 1992; accepted February 4, 1993.

Correspondence: Lee Frank, M.D., Ph.D, Pulmonary Research Center (R-120), University of Miami School of Medicine, P. O. Box 016960, Miami, FL 33101

Supported in part by American Heart Association, Florida Affiliate Grant-inAid Award 91GIA/733 and by the Departments of Medicine and Pediatrics Pulmonary Research Center.
Neonatal animals are generally much more resistant to the severe lung-damaging effects of prolonged exposure to hyperoxia than adult animals. Whereas adult animals of many tested species die within 3 to $5 \mathrm{~d}$ in $>95 \% \mathrm{O}_{2}$ with severe lung pathology (pulmonary edema, hemorrhage, and inflammatory cell influx), most newborn animals survive similar hyperoxic exposure for $>7$ to $10 \mathrm{~d}$ with much less evidence of acute lung injury (1-3). However, a unique consequence of hyperoxic exposure in the newborn is marked inhibition of the rapid lung growth and development that normally occurs in the early days of life in most newborn species. In the neonatal rat lung, for example, between postnatal d 4 to 14 , there normally occurs a very dynamic septation process by which the large immature terminal air spaces (saccules) present at birth are subdivided into many smaller mature terminal air spaces (alveoli), with a resultant several-fold increase in lung surface area for respiratory exchange (4-6). Exactly how hyperoxic exposure during this so-called "critical period" of lung development inhibits the coordinated process of alveolarization and surface area expansion of the newborn's lung is unknown.

However, the biochemical mechanism of cellular $\mathrm{O}_{2}$ toxicity is by now quite well established. Hyperoxia results in a marked increase in the normal rate of intracellular production of partially reduced and highly reactive $\mathrm{O}_{2}$ species that are by-products of aerobic metabolism. When produced in excess of the cell's capacity to detoxify them, these reactive $\mathrm{O}_{2}$ species are capable of causing diffuse cellular damage $(7,8)$. It is also well established that ionic iron (or other transition metals) is a major factor in promoting both $\mathrm{O}_{2}$ free-radical production as well as the subsequent cytotoxic interactions of $\mathrm{O}_{2}$ free radicals with their cellular lipid, protein, and nucleotide target molecules $(9,10)$.

Based on the assumption that $\mathrm{O}_{2}$-induced inhibition of neonatal lung development is similarly mediated by reactive $\mathrm{O}_{2}$ species, a variety of antioxidant and free radical scavenger agents have recently been tested in an attempt to prevent or ameliorate $\mathrm{O}_{2}$-induced lung growth inhibition, with varying degrees of success (11-13). The same rationale prompted our present studies using a prototype of a new class of compounds-the 21-AS, or lazaroids. These drugs have several relatively unique properties that in theory would make them well suited to counter $\mathrm{O}_{2}$ free radical-induced toxicity: $l$ ) being lipophilic, they should easily penetrate cell membranes reaching the intracellular sites of $\mathrm{O}_{2}$ radical production and attack; 2) as potent iron-chelators, they should be able to reduce the $\mathrm{Fe}^{++}$available for $\mathrm{Fe}$-dependent $\mathrm{O}_{2}$ free-radical reactions; and 3) as reportedly effective inhibitors of lipid peroxidation, they should be able to block $\mathrm{O}_{2}$-induced cell membrane oxidative damage $(14,15)$. We report herein a beneficial effect of treatment with this theoretically promising agent, U74389F, against both the acute and chronic effects on lung growth/developmental changes that early life exposure to hyperoxia can produce. We also discuss the possible implications of such treatment in the $\mathrm{O}_{2}$-requiring premature infant, whose lung 
is likely susceptible to the same type of early developmental inhibition by prolonged exposure to high fraction of inspired $\mathrm{O}_{2}$ levels.

\section{MATERIALS AND METHODS}

Animals and treatments. Adult male and female SpragueDawley albino rats to be used as breeders were obtained from Sprague-Dawley (Wilmington, MA). Rats were maintained in the Animal Care Facility at the University of Miami, fed standard laboratory food and water ad libitum, and kept on a 12-h light/ dark cycle. Rat pups were obtained from our own long-established rat breeding program. For each experiment, 4-d-old pups from four or eight litters were pooled and then randomly redistributed to the dams ( 10 to 12 pups/litter). The pups were treated with either daily s.c. injections of the 21-AS drug, U-74389F (kindly supplied by Dr. David Zimmerman, Upjohn, Kalamazoo, MI) in citrate vehicle $(0.02 \mathrm{M}$ citric acid, $0.0032 \mathrm{M}$ sodium citrate, $0.077 \mathrm{M}$ sodium chloride) at a dose of $15 \mathrm{mg} / \mathrm{kg}$ in a volume of $5 \mu \mathrm{L} / \mathrm{g}$ body weight or equivolume vehicle alone (designated the control group). Half of the 21-AS-treated and control litters were placed in hyperoxia, and half remained in room air for the 10-d experiments. Every $24 \mathrm{~h}$, the respective dams were rotated from the $\mathrm{O}_{2}$-exposed litters to the air-exposed litters to prevent $\mathrm{O}_{2}$ toxicity and resultant poor nurturing by the dams. Litters of pups were weighed daily to rule out poor nursing (comparatively poor pup weight gain) by any of the dams, but no dam replacements were needed throughout the course of these studies.

Exposures to hyperoxia were conducted as previously described (16) in $3.5-\mathrm{ft}^{3}$ plastic isolettes with regular monitoring of $\mathrm{O}_{2}\left(>95 \% \mathrm{O}_{2}\right)$ and $\mathrm{CO}_{2}$ concentrations $(<0.40 \%)$, temperature $\left(23\right.$ to $25^{\circ} \mathrm{C}$ ), and humidity ( 40 to $60 \%$ ). Exposures were continuous except for a daily 20 - to 30 -min interval to allow for animal maintenance, dam switching, and pup weighing and injection. NIH guidelines for humane animal treatment were followed in all experimental procedures, and the protocol was preapproved by the University of Miami Animal Welfare Committee.

Lung morphometry. For the morphologic studies, rat pups were killed by an overdose of pentobarbital at the end of the 10 d period in $>95 \% \mathrm{O}_{2}$ or room air. Lungs were fixed with $10 \%$ buffered formalin via a tracheal cannula, using a constant inflation pressure of $20 \mathrm{~cm} \mathrm{H}_{2} \mathrm{O}$ (fixative), maintained for $48 \mathrm{~h}$ before sectioning. No correction was made for tissue shrinkage. Lung volumes were measured by water displacement (17) and specific lung volumes (mL/100 $\mathrm{g}$ body weight) were calculated. From all lungs, similarly oriented sections from similar portions of the left lung and the right middle and lower lobes were stained with hematoxylin and eosin and initially examined to eliminate any sections with evidence of inadequate preparation (atelectasis). Morphometry was performed using a standard integrating eyepiece with a grid matrix composed of seven equal lines and 42 intercept bars (Zeiss). The coded slides were examined at $400 \times$ magnification, with 30 random fields counted per slide. We counted the number of times the intercept bars fell on lung tissue per field and the number of times the lines were crossed by tissue septa per field. $\mathrm{L}_{\mathrm{M}}$ was calculated using the formula (18):

$$
\mathrm{L}_{\mathrm{M}}=\frac{\text { Length of line } \times \text { no. of lines } \times \text { no. of fields }}{\text { Total no. of tissue intercepts }}
$$

where length of line is $0.21 \mathrm{~mm}$, number of lines is seven, and number of fields is $30 . \mathrm{L}_{\mathrm{M}}$ is a measure of the average air space diameter and decreases during the period of early postnatal lung maturation. ISA was calculated using the formula (19):

$$
\text { ISA }=\frac{4 \times \text { lung volume }}{\mathrm{L}_{\mathrm{M}}}
$$

ISA is essentially a measure of the amount of lung surface area available for respiratory exchange function, and ISA normally increases several-fold during the period of early postnatal lung maturation.

Percentage of air space was calculated by:

$$
\% \text { Air space }=\mathrm{P}_{\mathrm{A}} /\left(\mathrm{P}_{\mathrm{A}}+\mathrm{P}_{\Upsilon}\right) \times 100
$$

where $P_{A}$ is the mean number of intercept bars per lung field hitting air and $\mathrm{P}_{\mathrm{T}}$ is the mean number of intercept bars per lung field hitting tissue, with $\left(\mathrm{P}_{\mathrm{A}}+\mathrm{P}_{\mathrm{T}}\right)=42$ intercept bars per lung field.

The same lung sections used for quantitative morphometry were also stained with orcein to highlight lung elastin (black fibers). With coded slides, using the same seven-line grid matrix eyepiece at $400 \times$ magnification, we estimated the relative-length density of elastin fibers in lung parenchymal tissue using a technique for length-density measurement as described by Niewoehner and Kleinerman (20). Each line of the test system represented a plane perpendicular to the plane of the section. The section was screened parallel to each of the seven lines, and the number of intersections of the lines with black elastin fibers was recorded. Each of these intersections corresponds to a fiber transected by the test plane. No attempt was made to quantitatively estimate the dimension of the test plane perpendicular to the plane of the section (a few $\mu \mathrm{m}$ ), but because this was constant for all sections scanned, the number of transections yielded relative values rather than absolute values of length density. Thirty random fields per lung were counted (omitting fields in which large vessels or airways with circumferential elastin fibers were present), and the mean number of transections per lung field was calculated for each coded slide.

Similar methods of lung preparation and morphometric analysis were used for the follow-up (chronic) studies of 63-d-old rats that were exposed to hyperoxia (or room air) at age 4 to $14 \mathrm{~d}$ of life and thereafter kept in room air. In addition, to assess for right ventricular hypertrophy in these chronic animals, the right ventricle was carefully dissected away from the left ventricle and septum, and both portions were weighed to the nearest mg (11).

Finally, to assess for intraalveolar edema in the neonatal rats exposed to hyperoxia for $10 \mathrm{~d}$, the coded lung sections used for morphometric analysis were scanned for the presence of pinkstaining material within the lumen of the air spaces (proteinaceous edema fluid).

Lung biochemical analyses. Lung elastin content was assayed by the method of Naum and Morgan (21). After homogenization of the lungs in $0.15 \mathrm{M} \mathrm{NaCl}$ and centrifugation, $1.0 \mathrm{~mL}$ of $5 \mathrm{M}$ guanidine $\mathrm{HCl}, \mathrm{pH} 7.0$, was added to the pellet. Guanidine extraction continued for $24 \mathrm{~h}$ at room temperature in a shaking water bath. After centrifugation and a second 24-h extraction with guanidine, the residue was suspended in $1.0 \mathrm{~mL} \mathrm{H}_{2} \mathrm{O}$ and then autoclaved at $15-1 \mathrm{~b}$ pressure for $45 \mathrm{~min}$. After centrifugation, the precipitate was mixed with $1.0 \mathrm{~mL}$ of $\mathrm{H}_{2} \mathrm{O}$ and $1.0 \mathrm{~mL}$ of elastase solution $(0.1 \mathrm{mg}$ of purified elastase in $0.1 \mathrm{M}$ veronal acetate buffer, $\mathrm{pH} 8.8$ ) and incubated for $30 \mathrm{~min}$ at $37^{\circ} \mathrm{C}$ in a shaking water bath. Aliquots were then assayed for protein (elastin) content by the method of Lowry (22). Purified standards of elastin were treated as above for generation of a standard assay curve.

Two assays of lipid peroxidation products were performed for lung malondialdehyde content (left lungs) and for conjugated dienes (right lungs). Lung malondialdehyde concentrations were assayed by measuring thiobarbituric acid-reactive substances extracted into butanol (23). After perfusion and homogenization in $1.15 \% \mathrm{KCl}(10: 1$, vol/wt), $0.2 \mathrm{~mL}$ of $8.1 \% \mathrm{SDS}, 1.5 \mathrm{~mL}$ of $20 \%$ acetic acid, $\mathrm{pH} 3.5,2 \mathrm{~mL}$ of $0.8 \%$ thiobarbituric acid, and $10 \mu \mathrm{L}$ of butylated hydroxytoluene solution to equal $0.01 \%$ butylated hydroxytoluene were added to $0.3 \mathrm{~mL}$ of homogenate. The well mixed suspension was heated at $95^{\circ} \mathrm{C}$ for $60 \mathrm{~min}$. After cooling, $5 \mathrm{~mL}$ of butanol was added. After vigorous mixing followed by centrifugation at $4000 \mathrm{rpm}$ for $15 \mathrm{~min}$, the absorbance of the organic layer was read at $532 \mathrm{~nm}$ and compared to a standard curve of tetramethoxypropane. 
Conjugated dienes were determined by a modification of the method of Buege and Aust (24). After homogenization in 0.8 $\mathrm{mL}$ of $\mathrm{H}_{2} \mathrm{O} / \mathrm{g}$ lung tissue, $6.0 \mathrm{~mL} / \mathrm{g}$ lung tissue of chloroform:methanol $(2: 1)$ heated to $45^{\circ} \mathrm{C}$ were added to the homogenized samples. After vigorous mixing, an additional $2 \mathrm{~mL}$ of

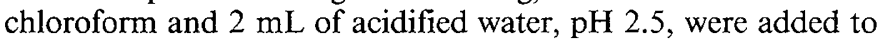
the homogenate. After centrifugation, the lower chloroform: $\mathrm{H}_{2} \mathrm{O}$ layer was removed by aspiration and dried under a flow of nitrogen gas. The residue was suspended in heptane, and the OD at $233 \mathrm{~nm}$ was compared to a heptane blank. Purified reagents for each of these biochemical assays were obtained from Sigma Chemical Co., St. Louis, MO. For each assay, the nonperfused accessory lobe of the lung was weighed before and after drying to constant weight in an $80^{\circ} \mathrm{C}$ oven to determine wet/dry weight ratios in the air and $\mathrm{O}_{2}$ treated and control groups. In addition to using the ratio as an index of pulmonary edema, it was used for expression of the assay results as absorption units or $\mathrm{nmol} / \mathrm{g}$ lung dry weight.

Statistical analysis. Hyperoxic survival rates of the treated versus control rat pups were compared by $\chi^{2}$ testing. Analysis of variance testing followed by Duncan's multiple-range testing was used for comparison of lung biochemical values and morphometric values, using $p<0.05$ as the level of significant differences between treatment groups (25).

\section{RESULTS}

Hyperoxic survival, lung injury, and lung biochemistry. There was no evidence for any serious toxic effects of 21-AS in the 4to 14-d-old rat pups. All the 21-AS-treated rats maintained in room air for $10 \mathrm{~d}$ survived, as did all the control pups. Similarly, weight gain remained comparable in both groups of room-air pups.

The data in Table 1 indicate that, although the 10-d survival rates of the 21-AS-treated animals was greater than the hyperoxia-exposed control pups (79 versus $70 \%$ ), these differences did not reach statistical significance $(p=0.08)$. However, there was evidence for decreased $\mathrm{O}_{2}$-induced lung injury in the 21-AS versus the control-group survivors, with reduced pulmonary edema by lung wet:dry weight ratios and, perhaps more definitively, by the histologic finding of intraalveolar edema in $39 \%$ of the $\mathrm{O}_{2}$-control-group lung sections versus only $18 \%$ of the $\mathrm{O}_{2}-$ 21-AS animal lung sections.

Lung lipid peroxidation was assessed by two methods, as generally recommended because of the vagaries of any single assay for in vivo lipid peroxide products (23). The results (Table 2 ) indicate that, after $3 \mathrm{~d}$ in hyperoxia, the $21-\mathrm{AS}$ group had a significantly smaller increase in malondialdehyde than the $\mathrm{O}_{2}$

Table 1. Comparative survival rates and lung edema: $10 \mathrm{~d}$ in hyperoxia*

\begin{tabular}{|c|c|c|c|}
\hline $\begin{array}{l}\text { Treatment } \\
\text { group }\end{array}$ & $\begin{array}{c}\text { Survival rate } \\
(\%)\end{array}$ & $\begin{array}{l}\text { Lung wet/dry wt } \\
\text { (ratio) }\end{array}$ & $\begin{array}{c}\text { Histologic } \\
\text { intraalveola } \\
\text { edema (no. } \\
\text { with edema/ } \\
\text { no. of lung } \\
\text { sections) }\end{array}$ \\
\hline Air controls & $68 / 68(100)$ & $5.13 \pm 0.15$ & $0 / 40(0)$ \\
\hline Air 21-AS & $67 / 67(100)$ & $5.14 \pm 0.20$ & $0 / 42(0)$ \\
\hline $\mathrm{O}_{2}$ controls & $51 / 73(70)$ & $6.05 \pm 0.49(\uparrow 18)$ & $19 / 49(39)$ \\
\hline $\mathrm{O}_{2} 21-\mathrm{AS}$ & $55 / 70(79)$ & $5.77 \pm 0.37(\uparrow 12) \dagger$ & $10 / 55(18) \dagger$ \\
\hline
\end{tabular}

* Four-d-old rat pups were exposed to $>95 \% \mathrm{O}_{2}$ or room air for $10 \mathrm{~d}$ and treated with either $21-\mathrm{AS}(15 \mathrm{mg} / \mathrm{kg} / \mathrm{d})$ or vehicle. Values are mean $\pm 1 \mathrm{SD} ; n=15$ /group for wet:dry ratios. For histologic sections, three to four sections per animal lung were examined, 12 to 16 animals per group, for presence or absence of pink-staining proteinaceous edema within the alveolar air spaces.

$\dagger$ Numbers in parentheses are percentages. $p<0.05$ between $\mathrm{O}_{2}$ controls and $\mathrm{O}_{2} 21$-AS groups. control group $(+16$ versus $+45 \%)$ when compared with the air controls. The conjugated diene levels at $3 \mathrm{~d}$ in hyperoxia, however, were lower in both $\mathrm{O}_{2}$-exposed groups than in the airexposed animal lungs-the $\mathrm{O}_{2}$ control value was $17 \%$ lower, whereas the 21-AS group value was $57 \%$ lower than the air control lung value. At $6 \mathrm{~d}$ in $\mathrm{O}_{2}$, malondialdehyde values were again higher in the $\mathrm{O}_{2}$ control ( $\uparrow 20 \%$ versus air control) than the 21 -AS group $(\downarrow 21 \%)$. The conjugated diene values at $6 \mathrm{~d}$ were elevated in both $\mathrm{O}_{2}$ groups versus the air control values, with slightly less of an increase in the 21 -AS animal lungs ( $\uparrow 31 \%)$ than in the $\mathrm{O}_{2}$ control lungs $(\uparrow 40 \%)$. Thus, the consistent finding for the lipid peroxidation results was lower malondialdehyde and conjugated diene levels in the 21-AS $\mathrm{O}_{2}$ rats compared with the $\mathrm{O}_{2}$ controls at both time points examined. However, because statistically the only significant difference between the $\mathrm{O}_{2}$-exposed group values was for the conjugated dienes at $3 \mathrm{~d}$, the lipid peroxidation data are not easy to interpret definitively.

Lung morphometry (acute and chronic). In each of three separate morphometric studies, there was evidence of a significant protective effect of 21-AS treatment against hyperoxia-induced inhibition of normal alveolarization and lung surface-area expansion ( $p<0.05$ difference versus $\mathrm{O}_{2}$ control values for $\mathrm{L}_{\mathrm{M}}$, ISA $/ 100 \mathrm{~g}$ for each study). The composite data are illustrated in Figure 1, which demonstrates the significantly smaller $\mathrm{L}_{M}$, the significantly expanded lung ISA, and, more physiologically meaningful, the expanded ISA/100 g body weight in the $\mathrm{O}_{2}-21$ AS-treated rat lungs compared with the lungs of the control $\mathrm{O}_{2}$ exposed group. Compared with the normal values for these three lung developmental parameters in the pooled air-exposed animal lungs, the mean values for the $\mathrm{O}_{2} 21-\mathrm{AS}$ versus the $\mathrm{O}_{2}$ control group, respectively, were as follows: $\mathrm{L}_{\mathrm{M}} \uparrow 13 \%$ versus $\uparrow 29 \%$; ISA, $\downarrow 9 \%$ versus $\downarrow 24 \%$; and ISA $/ 100 \mathrm{~g}, \downarrow 9 \%$ versus $\downarrow 21 \%(p<0.05$ for all comparisons between $\mathrm{O}_{2}$ groups).

Table 3 lists the comparative lung elastin data in the four groups of study rat pups, both the biochemical values and the morphometric results. Increased lung elastin deposition is integral to the normal postnatal restructuring (septation and alveolarization) of the newborn lung. By both measures of elastin in Table 3, it is apparent that the 21-AS-treated rat pups were significantly protected from hyperoxic inhibition of normal elastin deposition compared with the $\mathrm{O}_{2}$ control group. Figure 2 shows representative photomicrographs that reflect the elastin data in Table 3 as well as the morphometric data in Figure 1.

The data in Table 4 demonstrate the chronic consequences of early postnatal inhibition of lung development by hyperoxia. By early adulthood, the lungs of the $\mathrm{O}_{2}$ control group animals still demonstrate much-enlarged terminal air spaces and significantly reduced ISA/100 $\mathrm{g}$ compared with the lungs of normal adult animals. An ameliorative effect of 21-AS treatment during early postnatal hyperoxic exposure on these chronic lung alterations is clearly demonstrated by the data in Table 4 .

Finally, the detrimental effects of early hyperoxic exposure on normal pulmonary vascular development and the subsequent pulmonary hypertension and right ventricular hypertrophy that results from early hyperoxic exposure are indicated in Table 5. In the $\mathrm{O}_{2}$ control group, early hyperoxic exposure resulted in significantly increased right ventricular mass evident by each means of expression in Table 5. Treatment with 21-AS during early $\mathrm{O}_{2}$ exposure had a substantial protective effect against these chronic cardiopulmonary consequences-reducing right ventricular enlargement by 50 to $67 \%$ depending on the means of expressing this late sequel of early neonatal hyperoxia.

\section{DISCUSSION}

It is puzzling why newborn animals resist severe pulmonary $\mathrm{O}_{2}$ toxicity (florid pulmonary edema, hemorrhage, lethality) so well yet remain so susceptible to severe $\mathrm{O}_{2}$-induced inhibition of normal lung development. It has been rather well established that the biochemical basis for the comparatively marked $\mathrm{O}_{2}$ 
Table 2. Comparative measures of lung lipid peroxidation in air-and $\mathrm{O}_{2}$-exposed rat pups*

\begin{tabular}{|c|c|c|c|c|}
\hline \multirow[b]{2}{*}{ Treatment group } & \multicolumn{2}{|c|}{$3 \mathrm{~d}$} & \multicolumn{2}{|c|}{$6 \mathrm{~d}$} \\
\hline & $\begin{array}{c}\text { Malondialdehyde } \\
\text { (nmol/g dry wt; } \\
n=4)\end{array}$ & $\begin{array}{l}\text { Conjugated dienes } \\
(\mathrm{OD} / \mathrm{g} \text { dry wt; } \\
n=4)\end{array}$ & $\begin{array}{l}\text { Malondialdehyde } \\
\text { (nmol/g dry wt; } \\
n=4)\end{array}$ & $\begin{array}{l}\text { Conjugated dienes } \\
\text { (OD/g dry wt; } \\
n=3-4)\end{array}$ \\
\hline Air controls & $17.2 \pm 1.8$ & $23.4 \pm 1.1$ & $17.7 \pm 2.0$ & $15.1 \pm 2.8$ \\
\hline Air 21-AS & $15.5 \pm 1.9$ & $20.8 \pm 2.4$ & $15.0 \pm 2.7$ & $14.5 \pm 3.4$ \\
\hline $\mathrm{O}_{2}$ controls & $\begin{array}{c}25.0 \pm 2.1 \dagger \\
(\uparrow 45 \%)\end{array}$ & $\begin{array}{c}19.5 \pm 0.7 \\
(\downarrow 17 \%)\end{array}$ & $\begin{array}{c}21.2 \pm 5.3 \\
(\uparrow 20 \%)\end{array}$ & $\begin{array}{c}21.1 \pm 1.9 \dagger \\
(\uparrow 40 \%)\end{array}$ \\
\hline $\mathrm{O}_{2} 21-\mathrm{AS}$ & $\begin{array}{c}19.9 \pm 1.8 \\
(\uparrow 16 \%)\end{array}$ & $\begin{array}{c}10.0 \pm 1.3 \ddagger \\
(\downarrow 57 \%)\end{array}$ & $\begin{array}{c}14.0 \pm 1.0 \S \\
(\downarrow 21 \%)\end{array}$ & $\begin{array}{c}19.8 \pm 1.5 \\
(\uparrow 31 \%)\end{array}$ \\
\hline
\end{tabular}

* Four-d-old rat pups were exposed to $>95 \% \mathrm{O}_{2}$ or room air for 3 or $6 \mathrm{~d}$ and treated with either $21-\mathrm{AS}(15 \mathrm{mg} / \mathrm{kg} / \mathrm{d})$ or vehicle. Values are mean \pm 1 SEM. Values in parentheses are mean percentage change for $\mathrm{O}_{2}$ group value compared with air control group value ( $\uparrow$ or $\left.\downarrow\right)$.

$+p<0.05$ ( $>$ air groups).

$\ddagger p<0.05$ ( $<$ air groups); $p<0.05\left(<\mathrm{O}_{2}\right.$ control).

$\S p<0.05$ ( $<$ air control).

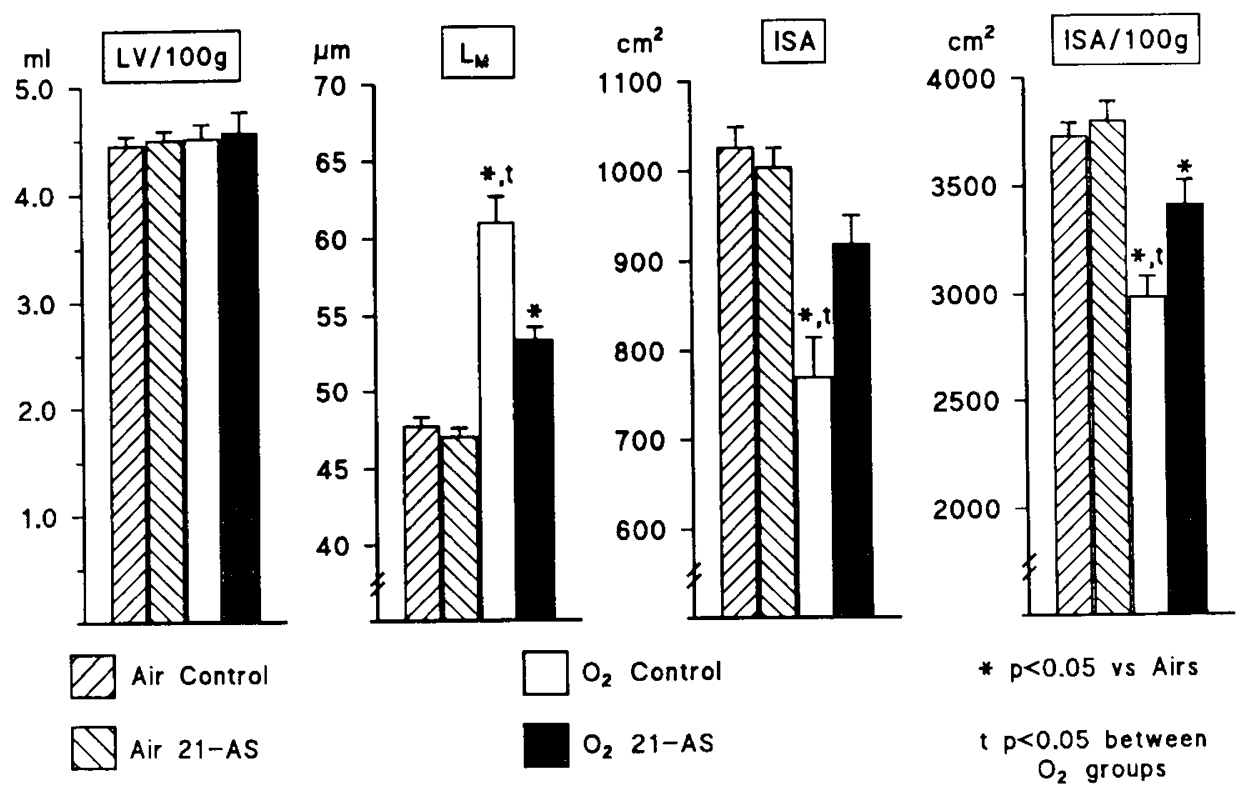

Fig. 1. Effects of $10-\mathrm{d}$ exposure to $>95 \% \mathrm{O}_{2}$ on lung morphometric parameters. $L V$, lung volume. Data are mean values \pm 1 SD bar for $12-15$ rat lungs/group. The 21-AS group received daily $15-\mathrm{mg} / \mathrm{kg}$ injections during $\mathrm{O}_{2}$ or air exposure (age 4-14 d); controls received equivolume diluent injections. ( $\mathrm{L}_{\mathrm{M}}$ normally decreases between 4 and $14 \mathrm{~d}$ of life, whereas ISA increases). ${ }^{*}, p<0.05 v s$ air control and air 21 -AS values; $\mathrm{t}, p<0.05$ between $\mathrm{O}_{2}$ control and $\mathrm{O}_{2}$ 21-AS values.

Table 3. Comparative lung elastin concentrations: $10 \mathrm{~d}$ in hyperoxia*

\begin{tabular}{lll}
\hline $\begin{array}{c}\text { Treatment } \\
\text { group }\end{array}$ & $\begin{array}{c}\text { Biochemical } \\
\text { elastin concentration } \\
\text { (mg/g dry lung wt) }\end{array}$ & $\begin{array}{c}\text { Morphologic elastin } \\
\text { relative length } \\
\text { density (elastic fiber } \\
\text { transections/hpf }\end{array}$ \\
\hline Air controls & $58.5 \pm 5.8$ & $17.9 \pm 1.5$ \\
Air 21-AS & $58.3 \pm 10.8$ & $18.1 \pm 1.7$ \\
$\mathrm{O}_{2}$ controls & $43.6 \pm 9.6(\downarrow 25 \%) \dagger$ & $12.1 \pm 1.4(\downarrow 33 \%) \dagger$ \\
$\mathrm{O}_{2} 21-\mathrm{AS}$ & $50.6 \pm 7.6(\downarrow 13 \%)$ & $15.4 \pm 1.6(\downarrow 14 \%) \dagger \ddagger$ \\
\hline
\end{tabular}

* Four-d-old rat pups were exposed to $>95 \% \mathrm{O}_{2}$ or room air for $10 \mathrm{~d}$ and treated with either $21-\mathrm{AS}(15 \mathrm{mg} / \mathrm{kg} / \mathrm{d})$ or vehicle. Values are mean $\pm 1 \mathrm{SD}$ for 12 samples/group for elastin biochemical assay and 10 lung sections examined/group for elastin morphometric study. hpf, highpower field $(\times 400)$.

$\dagger p<0.05$ vs air controls and air 21-AS.

$\ddagger p<0.05$ between $\mathrm{O}_{2}$ controls and $\mathrm{O}_{2} 21$-AS groups.

tolerance of neonatal versus adult animals is the ability of the newborn lung to respond to hyperoxic challenge with significantly increased pulmonary AOE levels, an adaptive response that adult animals seem unable to manifest during $>95 \% \mathrm{O}_{2}$ exposure $(1-3,26)$. Yet, despite this endogenous biochemical response, the newborn is apparently unable to protect its growing lung from hyperoxia-associated inhibition of normal lung development. Even when additional AOE elevations could be stimulated by prenatal dexamethasone treatment (27) or by exogenous AOE administration (28), the hyperoxia-induced inhibition of alveolarization persisted.

One possible explanation for this puzzling aspect of hyperoxic challenge in the newborn is the concept of site-specific $\mathrm{O}_{2}$ freeradical damage $(29,30)$. This concept maintains that a normal or even an augmented antioxidant defensive system may not be able to completely detoxify $\mathrm{O}_{2}$ free radicals at specific intracellular sites where these defenses are not very concentrated. The major AOE defenses are primarily cytosolic (CuZn-superoxide dismutase, glutathione peroxidase), mitochondrial (Mn-superoxide dismutase), and peroxisomal (catalase) in location. Other important nonenzymatic antioxidant components are also cytosolic (vitamin $\mathrm{C}, \beta$-carotene, glutathione) or integrated into lipid membranes of the cell (vitamin E) $(1,29,30)$. There are very sparse experimental data about intranuclear antioxidant capacities (29-31), and it has been suggested that $\mathrm{O}_{2}$ free radicals generated in or in close proximity to the nucleus may readily instigate damaging reactions with vital nuclear components 


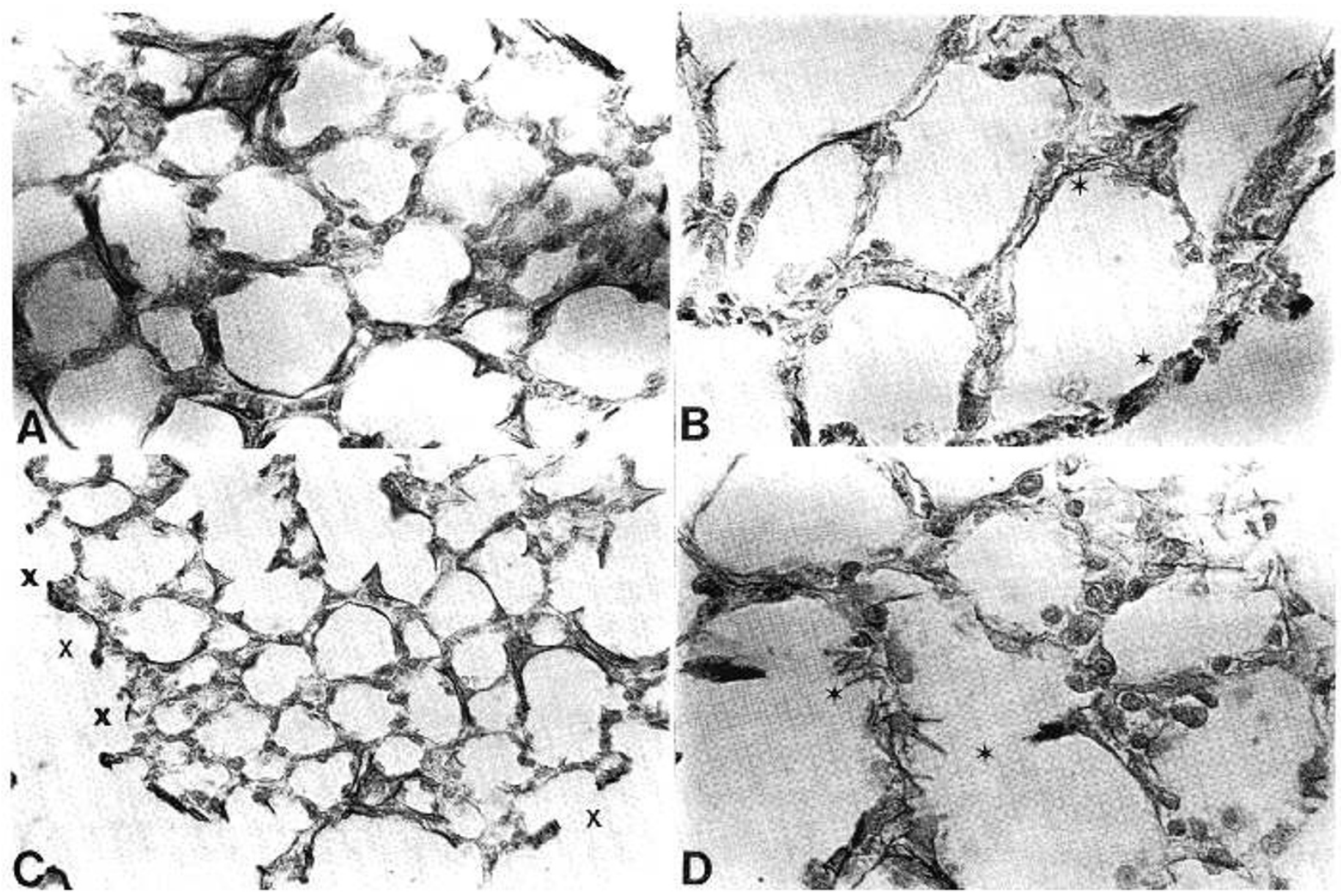

Fig. 2. Comparative light-level micrographs of representative lung sections from air- and hyperoxia-exposed rat pups age $14 \mathrm{~d}$ (exposure period age 4-14 d). Orcein stain to emphasize elastin fibers. $A$, Air, original magnification $160 \times ; B, \mathrm{O}_{2}, 160 \times ; C$, air, 100×; and $D, \mathrm{O}_{2}, 100 \times$. Note the smaller and more homogeneous alveoli size in the air- $(A)$ vs the $\mathrm{O}_{2}$-exposed rat lungs $(B)$ and the more circumferential arrangement of the darkstaining elastin fibers. After hyperoxia $(B)$, not only is the relative length density of fibers reduced and the circumferential arrangement around the alveoli lacking, but the fibers themselves in the $\mathrm{O}_{2}$-exposed lungs appear either aggregated or frayed in areas $\left({ }^{*}\right)$. Note again in the air lung at lower magnification $(C)$ the rather homogeneous small alveoli, some showing circumferential elastin fibers. Mouths of alveoli coming off terminal airway or alveolar duct tend to have dense elastin deposits $(X)$. In the $\mathrm{O}_{2}$-exposed lung $(D)$, the alveoli are again much larger and more heterogeneous in diameter, and frayed elastin fibers $\left({ }^{*}\right)$ and more haphazard elastin deposition than in the air-exposed normal 14-d rat lung are evident.

Table 4. Lung morphometry of adult rats exposed to hyperoxia as newborns*

\begin{tabular}{cccc}
\hline & Air space & & \\
Treatment group & $(\%)$ & $\mathrm{L}_{\mathrm{M}}(\mu \mathrm{m})$ & ISA $\left(\mathrm{cm}^{2}\right) / 100 \mathrm{~g}$ \\
\hline Air controls $(n=8)$ & $75.4 \pm 1.3$ & $53.3 \pm 2.3$ & $1483 \pm 138$ \\
$\mathrm{O}_{2}$ controls $(n=5)$ & $80.1 \pm 1.0 \dagger$ & $79.8 \pm 3.0 \dagger$ & $1304 \pm 59 \dagger$ \\
& & $(\uparrow 50 \%)$ & $(\downarrow 12 \%)$ \\
$\mathrm{O}_{2} 21-\mathrm{AS}(n=5)$ & $77.1 \pm 1.2 \dagger \ddagger$ & $69.2 \pm 3.7 \dagger \ddagger$ & $1424 \pm 135$ \\
& & $(\uparrow 30 \%)$ & $(\downarrow 4 \%)$ \\
\hline
\end{tabular}

* Sixty-three-d-old rats were exposed to $>95 \% \mathrm{O}_{2}$ (or room air) from age 4 to $14 \mathrm{~d}$ and then returned to room air. Rats were treated with 21 AS $(15 \mathrm{mg} / \mathrm{kg} / \mathrm{d})$ or vehicle during exposure period in hyperoxia. Values are means $\pm 1 \mathrm{SD}$ for $n$ rats/group. Values for air-21-AS-treated group were similar to those for air-diluent-treated group and are pooled here as air control group.

$\dagger p<0.05$ vs air control value.

$\ddagger p<0.05$ between $\mathrm{O}_{2} 21$-AS and $\mathrm{O}_{2}$ control group.

(DNA) (29-31). Decreased cell proliferation is a well-known concomitant of hyperoxic exposure in the newborn $(1,8,13,16$, 26,32 ). Because the process of septation undoubtedly involves a very coordinated proliferation of specific lung cells, an inhibitor of DNA synthesis like hyperoxia, or disruption of DNA integrity by $\mathrm{O}_{2}$ free radicals, can easily be viewed as causing discoordination of this developmental process.

Because $\mathrm{Fe}^{++}$is believed necessary to initiate damaging DNA$\mathrm{O}_{2}$ radical interactions $(1,3,9,10,29)$, Fe chelators may be an effective mode of treatment to "site-specifically" prevent oxidative DNA degradation. The 21-AS drugs are reportedly manyfold more potent $\mathrm{Fe}$ chelators than the commonly used agents deferoxamine, or o-phenanthroline, or EDTA, and more easily penetrate cells due to their lipophilic chemical nature $(14,33)$. The 21-AS drugs are also reportedly very effective inhibitors of lipid peroxidation by means of scavenging lipid peroxyl radicals $(14,33,34)$. Lipid peroxidation is believed by many to be a key mechanism of cellular injury and cell death caused by $\mathrm{O}_{2}$ radicals; and hyperoxic pulmonary edema is considered a reflection of altered lung cell membrane permeability due to oxidative attack on unsaturated membrane lipids $(3,8,10,13,23,24,35)$. Very recent evidence from electron paramagnetic resonance studies suggests that the 21-AS drugs may also directly scavenge hydroxyl radicals in both in vitro and in vivo test systems (36).

Because of these multiple actions proposed for the 21-AS drugs- $-\mathrm{Fe}^{++}$chelation, $\mathrm{O}_{2}$ radical scavenging, and prevention of lipid peroxidation chain reactions-the prototype agent, $\mathrm{U} 74389 \mathrm{~F}$, seemed to us to be a good treatment choice to test under hyperoxic conditions. The overall morphometric results would strongly suggest that U74389F treatment did indeed have 
Table 5. Right heart changes in adult rats exposed to hyperoxia as newborns*

\begin{tabular}{|c|c|c|c|c|}
\hline Treatment group & BW & $\mathrm{RV} / \mathrm{BW}$ & $\mathrm{RV} / \mathrm{LV}+$ septum & $\begin{array}{c}\mathrm{RV} / \mathrm{RV}+\mathrm{LV}+\text { septum } \\
(\%) \\
\end{array}$ \\
\hline Air controls $(n=8)$ & $277 \pm 22$ & $0.065 \pm 0.005$ & $0.320 \pm 0.023$ & $24.2 \pm 1.3$ \\
\hline $\mathrm{O}_{2}$ controls $(n=5)$ & $288 \pm 24$ & $\begin{array}{c}0.093 \pm 0.014 \dagger \\
(\uparrow 43 \%)\end{array}$ & $\begin{array}{c}0.496 \pm 0.085 \dagger \\
(\uparrow 55 \%)\end{array}$ & $\begin{array}{c}33.0 \pm 3.8 \dagger \\
(\uparrow 36 \%)\end{array}$ \\
\hline $\mathrm{O}_{2} 21-\mathrm{AS}(n=5)$ & $273 \pm 16$ & $\begin{array}{c}0.079 \pm 0.007 \dagger \ddagger \\
(\uparrow 22 \%)\end{array}$ & $\begin{array}{c}0.382 \pm 0.054 \ddagger \\
(\uparrow 19 \%)\end{array}$ & $\begin{array}{c}27.6 \pm 2.7 \dagger t \\
(\uparrow 14 \%)\end{array}$ \\
\hline
\end{tabular}

\footnotetext{
* Sixty-three-d-old rats were exposed to $>95 \% \mathrm{O}_{2}$ (or room air) from age 4 to $14 \mathrm{~d}$ and then returned to room air. Rats were treated with 21 -AS $(15 \mathrm{mg} / \mathrm{kg} / \mathrm{d})$ or vehicle during exposure period in hyperoxia. Values are means \pm 1 SD for $n$ rats/group. All values for air 21-AS animals were similar to air-diluent-treated rats and are pooled here as air control group. RV, right ventricle wt; LV, left ventricle wt; BW, body wt.

$\dagger p<0.05 v s$ air control value.

$\ddagger p<0.05$ between $\mathrm{O}_{2} 21$-AS and $\mathrm{O}_{2}$ control group.
}

a substantial protective effect against the acute inhibition of lung development associated with neonatal hyperoxia. The lipid peroxidation data give partial support to the expected effects of 21 AS treatment (Table 2). Due to the vagaries of any single assay for in vivo assessment of lipid peroxide products (23), both thiobarbituric acid-reactive products (malondialdehyde) and conjugated dienes were assessed. Postmortem lipid peroxidation or lipid peroxidation due to the preparative procedures for the assays should have been blocked by the addition of butylated hydroxytoluene to the assay solutions. The results consistently showed lower malondialdehyde and conjugated diene levels in the 21-AS-treated rat lungs in $\mathrm{O}_{2}$ compared with the $\mathrm{O}_{2}$ controls at both time points examined. (The relatively small number of lung samples tested may account for the lack of statistical significance in these single experimental studies.) The reported action of 21-AS as a potent $\mathrm{Fe}^{++}$chelator and as a direct antioxidant agent (scavenger of hydroxyl free radical) was not tested in these studies.

Elastin is considered to be integrally involved in the septation process as the electron microscopic demonstration of elastin near the tips of the secondary septa that subdivide the saccules into smaller alveoli would suggest (6). Hyperoxia is reported to inhibit lung elastin synthesis (37), and this may be another key means (in addition to inhibiting cell proliferation) by which hyperoxia disrupts the orderly septation/alveolarization process. Both the biochemical and morphometric elastin data (Table 3) support this effect of hyperoxia, as well as give evidence for a protective sparing of elastin development in the 21-AS treatment group.

Hyperoxic exposure during the first 2 wk of life [the so-called "critical period" for lung restructuring (38)] permanently alters adult lung morphology $(1,37-40)$. After early postnatal exposure to hyperoxia, the mean diameter of the terminal air spaces remains approximately similar to the lung saccule diameter at birth, and the alveoli in the adult animal are found to be much enlarged compared with the alveolar diameter in the normal adult animal, with the total number of alveoli significantly reduced (40). Additionally, with exposure to hyperoxia in early life, chronic vascular alterations occur manifested by extension of muscular walls into more distal and smaller lung arteries that are normally nonmuscularized, and pulmonary hypertension with increased pulmonary vascular resistance develops (41-44). Shaffer et al. (42) and Thibeault et al. (44) have demonstrated the consequences of these vascular changes in their studies of early postnatal hyperoxia, with resultant right ventricular hypertrophy (cor pulmonale) $2^{\circ}$ to elevated pulmonary vascular pressures in the adult animals. The data in Tables 4 and 5 confirm these chronic changes. And, as with the acute lung changes after early life exposure to hyperoxia, 21-AS treatment was found to have a meaningful protective effect versus the chronic lung structural sequelae, as well as against right heart hypertrophic changes.

Although the period of rapid alveolarization in the newborn rat lung is very abbreviated compared with the human situation, the hyperoxic effects noted in the developing rat lung may have direct implications for the lung of the prematurely born human infant. We suggest this because: 1 ) very low birth weight premature infants may require elevated $\mathrm{F}_{\mathrm{I}} \mathrm{O}_{2}$ therapy for periods of months; and, 2) this hyperoxic treatment is occurring at a time when the fetal lung should normally be entering its most rapid phase of lung development and surface-area expansion (with the normal formation of an estimated $40 \times 10^{6}$ alveoli between 26 wk gestation and term) $(45,46)$. In recent years, several morphometric studies of the lungs of human infants who died with chronic lung disease (bronchopulmonary dysplasia) have clearly illustrated much-enlarged terminal air spaces, markedly reduced total number of alveoli, and proportionately reduced lung internal surface area (47-49). These changes indeed appear quite similar to the findings of morphometric studies in the hyperoxiaexposed newborn animal. The recent pathologic study by Margraf et al. (47) also demonstrates the reduced elastin fiber deposition and altered (frayed) appearance of the elastin fibers in the lungs from premature infants who died from chronic lung disease after long-term $\mathrm{O}_{2}$ treatment. The degree of inhibition of normal lung development in these $\mathrm{O}_{2}$-requiring infants with bronchopulmonary dysplasia is dramatic, with a total lung alveoli complement of only 20 to $40 \times 10^{6}$ versus 60 to $200 \times 10^{6}$ for agematched control infants and internal respiratory exchange surface areas totaling $\leq 1.0 \mathrm{~m}^{2}$ versus the normal values of 2 to 6 $\mathrm{m}^{2}(49)$.

Thus, in well-established experimental models, the development of effective agents to specifically counteract the vulnerability of the rapidly developing lung to the potent growth inhibitory effects of hyperoxic exposure may hold future promise for clinical application in the large population of $\mathrm{O}_{2}$-requiring tiny premature infants who are at risk of developing chronic lung disease and a poor respiratory outcome.

Acknowledgments. The authors thank Lalitha T. Price, Ph.D., and Miguel Martinez, B.S., for their excellent technical assistance, and Martha Sanchez for her patient help with the preparation of the manuscript. We thank Dr. David Zimmerman of Upjohn Co. for his generous provision of the 21-AS compound, U74389F.

\section{REFERENCES}

1. Frank L 1991 Developmental aspects of experimental pulmonary oxygen toxicity. Free Rad Biol Med 11:463-494

2. Frank L, Bucher JR, Roberts RJ 1978 Oxygen toxicity in neonatal and adult animals of various species. J Appl Physiol 45:699-704

3. Heffner JE, Repine JE 1989 Pulmonary strategies of antioxidant defense. Am Rev Respir Dis 140:531-554

4. Burri PH, Dbaly J, Weibel ER 1974 The postnatal growth of the rat lung. I. Morphometry. Anat Rec 178:711-730

5. Burri PH 1974 The postnatal growth of the rat lung. IIl. Morphology. Anat Rec 180:77-98

6. Burri PH, Weibel ER 1977 Ultrastructure and morphometry of the developing lung. In: Hodson WA (ed) Development of the Lung. Marcel Dekker, New York, pp 215-268

7. Freeman BA, Crapo JD 1982 Biology of disease. Free radicals and tissue injury. Lab Invest 47:412-426

8. Southorn PA, Powis G 1988 Free radicals in medicine. I. Chemical nature and biologic reactions. Mayo Clin Proc 63:381-390

9. Thomas CE, Aust SD 1989 Role of metals in oxygen radical reactions and 
oxidative stress. In: Miguel J, Quintanilha AT, Weber H (eds) Handbook of Free Radicals and Antioxidants in Biomedicine. CRC Press, Boca Raton, FL, pp 37-48

10. Halliwell B, Gutteridge JMC 1986 Iron and free radical reactions: two aspects of antioxidant protection. Trends Biochem Sci 11:372-375

11. Shaffer SG, O'Neill DH, Thibeault DW 1987 Administration of bovine superoxide dismutase fails to prevent chronic pulmonary sequelae of neonatal oxygen exposure in the rat. J Pediatr 1 10:942-946

12. Frank L 1987 Oxygen toxicity in neonatal rats: the effect of endotoxin treatment on survival during and post- $\mathrm{O}_{2}$ exposure. Pediatr Res $21: 109-115$

13. Roberts RJ, Frank L 1984 Developmental consequences of oxygen toxicity. In: Kacew S, Reasor MJ (eds) Toxicology and the Newborn. Elsevier Biomedical Press, Amsterdam, pp 142-171

14. Braughler JM, Pregenzer JF, Chase RL, Duncan LA, Jacobsen EJ, McCall JM 1987 Novel 21-amino steroids as potent inhibitors of iron-dependent lipid peroxidation. J Biol Chem 262:10438-10440

15. Haynes Jr J, Seibert A, Bass JB, Taylor AE 1990 U74500A inhibition of oxidant-mediated lung injury. Am J Physiol 259:H144-H148

16. Frank L, Groseclose EE 1982 Oxygen toxicity in newborn rats: the adverse effects of undernutrition. J Appl Physiol 53:1248-1255

17. Scherle WA $1970 \mathrm{~A}$ simple method for volumetry of organs in quantitative stereology. Mikroskopie 26:57-60

18. Thurlbeck WM, Galaugher W, Mathers J 1981 Adaptive response to pneumonectomy in puppies. Thorax 36:414-427

19. Weibel ER 1963 Morphometry of the Human Lung. Academic Press, New York, pp 51-73

20. Niewoehner DE, Kleinerman J 1977 Morphometric study of elastic fibers in normal and emphysematous human lungs. Am Rev Respir Dis 115:15-21

21. Naum Y, Morgan TE 1973 A microassay for elastin. Anal Biochem 53:392396

22. Lowry OH, Rosebrough NJ, Farr AL, Randall RJ 1951 Protein measurement with the Folin phenol reagent. J Biol Chem 183:265-275

23. Ohkawa H, Ohishi N, Yagi K 1979 Assay for lipid peroxides in animal tissues by thiobarbituric acid reactions. Anal Biochem 95:351-358 24. Buege JA, Aust SD 1978 Microsomal lipid peroxidation. Methods Enzymol

25. Steel RG, Torrie J 1966 Principles and Procedures of Statistics. McGraw Hill, New York, pp 99-131

26. Bucher JR, Roberts RJ 1981 The development of the newborn rat lung in hyperoxia: a dose response study of lung growth, maturation, and changes in antioxidant enzyme activities. Pediatr Res 15:999-1008

27. Frank L 1992 Prenatal dexamethasone treatment improves survival of newborn rats during prolonged high $\mathrm{O}_{2}$ exposure. Pediatr Res 32:215-221

28. Tanswell AK, Freeman BA 1987 Liposome-entrapped antioxidant enzymes prevent lethal $\mathrm{O}_{2}$ toxicity in the newborn rat. J Appl Physiol 63:347-352

29. Chevion M 1988 A site-specific mechanism for free radical induced biological damage: the essential role of redox-active transition metals. Free Rad Biol Med 5:27-37

30. Touati D 1988 Molecular genetics of superoxide dismutases. Free Rad Biol Med 5:393-402

31. Yusa T, Crapo JD, Freeman BA 1984 Hyperoxia enhances lung and liver nuclear superoxide generation. Biochim Biophys Acta 793:167-174
32. Northway Jr WH, Petriceks R, Shahinian L 1972 Quantitative aspects of oxygen toxicity in the newborn: inhibition of lung DNA synthesis in the mouse. Pediatrics 50:67-72

33. Braughler JM, Pregenzer JF 1989 The 21-aminosteroid inhibitors of lipid peroxidation: reactions with lipid peroxyl and phenoxy radicals. Free Rad Biol Med 7:125-130

34. Hall ED, Pazara KE, Braughler JM, Linseman KL, Jacobsen EJ 1990 Nonsteroidal lazaroid U78517F in models of focal and global ischemia. Stroke 21(suppl III):III83-III87

35. Halliwell B, Gutteridge JMC 1990 Role of free radicals and catalytic metal ions in human disease: an overview. In: Packer L, Glazer AN (eds) Oxygen Radicals in Biological Systems, Methods in Enzymology, Vol 186. Academic Press, San Diego, pp 1-85

36. Hall ED, Yonkers PA, Andrus PK, Cox JW, Anderson DK 1992 Biochemistry and pharmacology of lipid antioxidants in acute brain and spinal cord injury. J Neurotrauma 9(Suppl 2):S425-S442

37. Bruce MC, Pawlowski R, Tomashefski Jr JF 1989 Changes in lung elastic fiber structure and concentration associated with hyperoxic exposure in the developing rat lung. Am Rev Respir Dis 140:1067-1074

38. Massaro D, Teich N, Maxwell S, Massaro GD, Whitney P 1985 Postnatal development of alveoli: regulation and evidence for a critical period in rats. J Clin Invest 76:1297-1305

39. Randall SH, Mercer RR, Young SL 1990 Neonatal hyperoxia alters the pulmonary alveolar and capillary structure in 40-day old rats. Am J Pathol 136:1259-1266

40. Blanco LN, Massaro GD, Massaro D 1989 Alveolar dimensions and number: developmental and hormonal regulation. Am J Physiol 257:L240-L247

41. Roberts RJ, Weesner KM, Bucher JR 1983 Oxygen-induced alterations in lung vascular development in the newborn rat. Pediatr Res 17:368-375

42. Shaffer SG, O'Neill D, Bradt SK, Thibeault DW 1987 Chronic vascular pulmonary dysplasia associated with neonatal hyperoxia exposure in the rat. Pediatr Res 21:14-20

43. Wilson WL, Mullen M, Olley PM, Rabinovitch M 1985 Hyperoxia-induced pulmonary vascular and lung abnormalities in young rats and potential for recovery. Pediatr Res 19:1059-1067

44. Thibeault DW, Mabry S, Rezaiekhaligh M 1990 Neonatal pulmonary oxygen toxicity in the rat and lung changes with aging. Pediatr Pulmonol 9:96-108

45. Langston C, Kida K, Reed M, Thurlbeck WM 1984 Human lung growth in late gestation and in the neonate. Am Rev Respir Dis 129:607-613

46. Tomashefski Jr JF, Vawter GF, Reid LM 1985 Pathological observations on infants who do not survive the respiratory distress syndrome. In: Nelson GH (ed) Pulmonary Development: Transition from Intrauterine to Extrauterine Life. Marcel Dekker, New York, pp 387-429

47. Sobonya RE, Logvinoff MM, Taussig LM, Theriault T 1983 Morphometric analysis of the lung in prolonged bronchopulmonary dysplasia. Pediatr Res 16:969-972

48. Hislop AA, Wigglesworth JS, Desai R, Aber V 1987 The effects of preterm delivery and mechanical ventilation on human lung growth. Early Hum Dev 15:147-164

49. Margraf LR, Tomashefski Jr JF, Bruce MC, Dahms, BB 1991 Morphometric analysis of the lung in bronchopulmonary dysplasia. Am Rev Respir Dis 143:391-400 